\title{
cemento y prefabricación
}

\author{
A. JOISEL \\ Director del Laboratorio del CERILH \\ Revue des Materiaux de Construction n. ${ }^{\circ} 628$, enero 1968 , págs. 3-10
}

\section{INTRODUCCION}

El hormigón en prefabricación se caracteriza por un cierto número de particularidades que resultan de la necesidad de realizar rápidamente construcciones de calidad, con un mínimo de mano de obra.

El cemento, constituyente noble del hormigón, tiene naturalmente un papel eminente en la adquisición de las calidades que le son exigidas a dicho hormigón.

\section{PRINCIPIOS DE LA HIDRATACION}

Los constituyentes hidráulicos del cemento se ponen en solución en el agua añadida para el amasado, donde precipitan, como expuso ya Le Chatelier, bajo forma de hidratos estables que aseguran la ligazón entre los granos del hormigón.

Pero la hidrólisis de los constituyentes del cemento se hace con cierta individualidad; su disolución es incongruente. Este es el caso particularmente para el silicato tricálcico, constituyente principal del portland: su resistencia mecánica a la temperatura ordinaria en las primeras edades se debe esencialmente a la cristalización, en los intersticios acuosos, del hidróxido cálcico naciente (portlandita) (fig. 1). ( $\mathrm{S}=\mathrm{SiO}_{2} ; \mathrm{A}=\mathrm{Al}_{2} \mathrm{O}_{3} ;$ $\mathrm{C}=\mathrm{CaO} ; \mathrm{H}=\mathrm{H}_{2} \mathrm{O}$ ).

El endurecimiento de los silicatos amasados se hace pues progresivamente, por un aumento continuo de concentración de los intersticios y, en consecuencia, tanto más deprisa cuanto el clínker es más rico en alita $\left(\mathrm{SC}_{3}\right)$, es decir, cuando es más rico en cal.

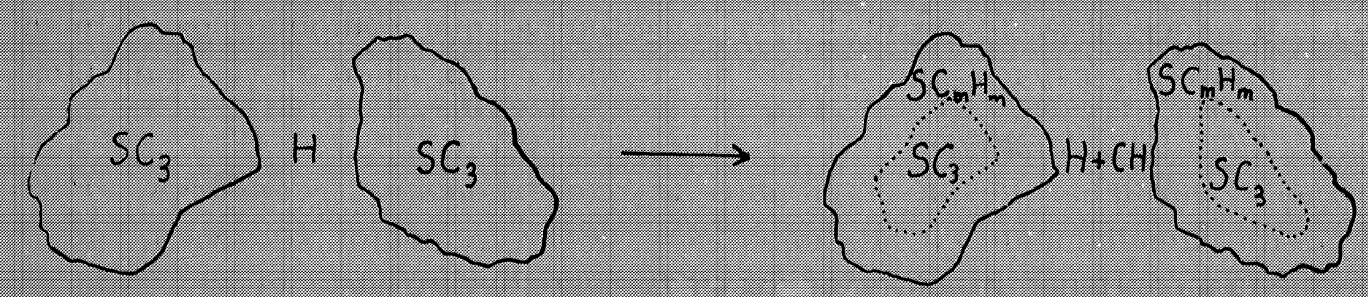

118. 1. 
Para el aluminato, no solamente la cal sino también la alúmina pasa a la disolución (fig. 2).

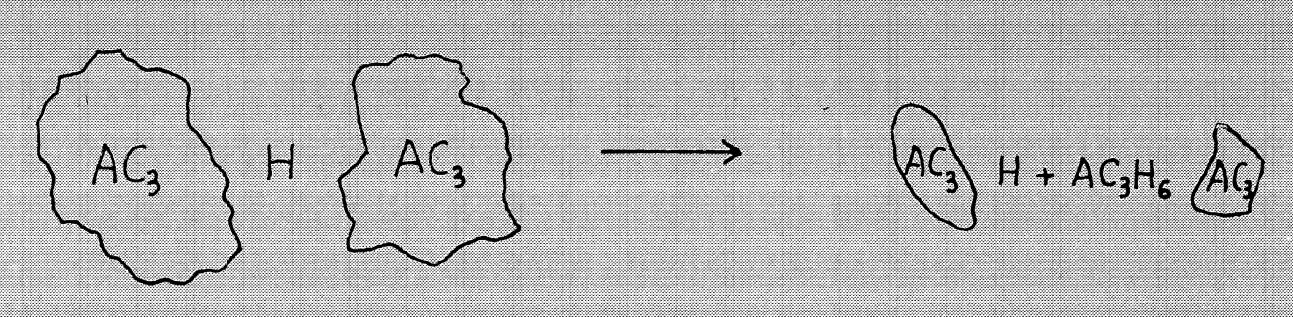

Fis. 2.

Mientras se hidrata el aluminato, la unión entre dos de sus granos no puede ser sólida porque su superficie desaparece disolviéndose. El aumento notable de resistencia no comienza prácticamente hasta que la mayor parte de los granos hayan pasado completamente a la solución; entonces es rápido.

El aluminato se hidrata tanto más deprisa cuanto más rico es en cal; en consecuencia, si este aluminato es pobre en cal (cemento aluminoso), el cemento aluminoso es de fraguado lento y de endurecimiento rápido; si el aluminato es muy rico en cal (aluminato tricálcico de un portland sin yeso, cemento rápido), el cemento es de fraguado rápido y de endurecimiento rápido.

De este modo, la hidratación de los silicatos produce la liberación de hidróxido cálcico que cristaliza en "portlandita", mientras que los coloides de los aluminatos precipitan en el seno de los intersticios acuosos que pueden ya contener otros cuerpos en solución: se pueden encontrar sulfoaluminatos, cloroaluminatos, carboaluminatos, etc.

Como los silicatos y los aluminatos cálcicos son sales de ácidos débiles y base fuerte, el $p H$ del agua de amasado adquiere rápidamente un valor elevado, del orden de 12 ó 13 .

\section{CONSTITUYENTES DE LOS CEMENTOS}

La hidratación del clínker portland depende, esencialmente, de los silicatos bi- y tricálcico y del aluminato tricálcico.

El cemento aluminoso contiene, principalmente, aluminatos de composición próxima al aluminato monocálcico.

La escoria granulada de horno alto empleada en las fábricas de cemento contiene silicoaluminatos cálcicos vítreos cuya composición potencial es próxima a $\mathrm{S}_{3} \mathrm{AC}_{6}$.

Las puzolanas naturales o artificiales (cenizas volantes) son igualmente vítreas. Contienen del orden del $50 \%$ de sílice y $30 \%$ de alúmina, que combinan parcialmente, en frío, con el hidróxido cálcico que se les ha añadido o procede de la hidratación del clínker.

Escorias y puzolanas llevan el nombre de "constituyentes secundarios". Participan en un $20 \%$ aproximadamente en la composición de los cementos franceses: dos tercios de estos cementos contienen proporciones variadas que llegan hasta el $85 \%$ (de escoria). 
La cal grasa $\mathrm{Ca}(\mathrm{OH})_{2}$ no es un conglomerante hidráulico. No endurece más que por carbonatación, a menos que pueda combinarse con sílice pulverulenta en autoclave, a unos $150^{\circ} \mathrm{C}$ aproximadamente.

La "cal hidráulica" es en su origen una mezcla de cal grasa y diversos silicatos y aluminatos de cal. Hoy, frecuentemente, es una mezcla de clínker de portland, escoria, puzolana e inerte (caliza, marga), molida a gran finura.

El cemento "bastardo" es una mezcla de portland y cal, que utiliza la resistencia conferida por el portland y la plasticidad aportada por la cal. Se eligen las proporciones de estos dos conglomerantes compatibles, en función de las necesidades.

\section{ADITIVOS}

Hay tres grandes categorías de aditivos que se mezclan eventualmente en proporciones variadas.

1) Los aditivos insolubles en el agua de amasado son polvos o emulsiones; es particularmente importante su granulometría.

2) Los aditivos solubles o miscibles en el agua de amasado son principalmente aceleradores o retardadores cuando actúan sobre la disolución de los componentes del cemento.

Los aceleradores son esencialmente:

- ácidos que aceleran la disolución de la cal;

- bases que aceleran la disolución de la sílice y la alúmina;

- sales ionizables de estos ácidos o bases.

Por ejemplo, el ácido clorhídrico o los cloruros aceleran la disolución de la cal de los silicatos; la sosa acelera la disolución de la sílice y de la alúmina de todos los silicatos y aluminatos y, por tanto, acelera todos los cementos; ocurre lo mismo con las sales sódicas de ácidos débiles: carbonatos, silicatos, aluminatos, etc.

Los iones de los ácidos más fuertes aceleran los cementos más básicos: cloruros para los portland. Las bases más fuertes aceleran los cementos más ácidos: álcalis para las puzolanas, escorias y cementos aluminosos. Pero estas dos aceleraciones son esencialmente distintas:

- Si se añade al agua de amasado un cloruro $\mathrm{Cl}^{-}$no se facilita la disolución de la sílice de los silicatos (con el pH elevado del agua), en tanto que se acelera la disolución de la cal. La textura de la pasta hidratada, con o sin cloruro, no es esencialmente distinta. Las resistencias finales no son tampoco muy distintas. Simplemente, una disolución acelerada da lugar a una cristalización más rápida, por tanto menos homogénea, y a una resistencia final un poco menor: para los retardadores (en dosis conveniente) que perturban la disolución de la cal, se obtiene por el contrario una resistencia final mejorada.

- Si se añade al agua de amasado hidróxido sódico, puede retardarse un poco la disolución de la cal del silicato; pero, sobre todo, la disolución de la sílice tiene lugar desde el principio. Ya no existe la disolución de los silicatos conforme a la figura 1, sino en cierta medida de acuerdo con la figura 2: en la superficie de los granos la sílice entra en disolución. Los iones $\mathrm{Na}^{+}$quedan en solución, pues 
los silicatos están saturados o sobresaturados en cal. El resultado es que las resistencias finales son más débiles que con los cloruros para la misma aceleración inicial (fig. 3.)

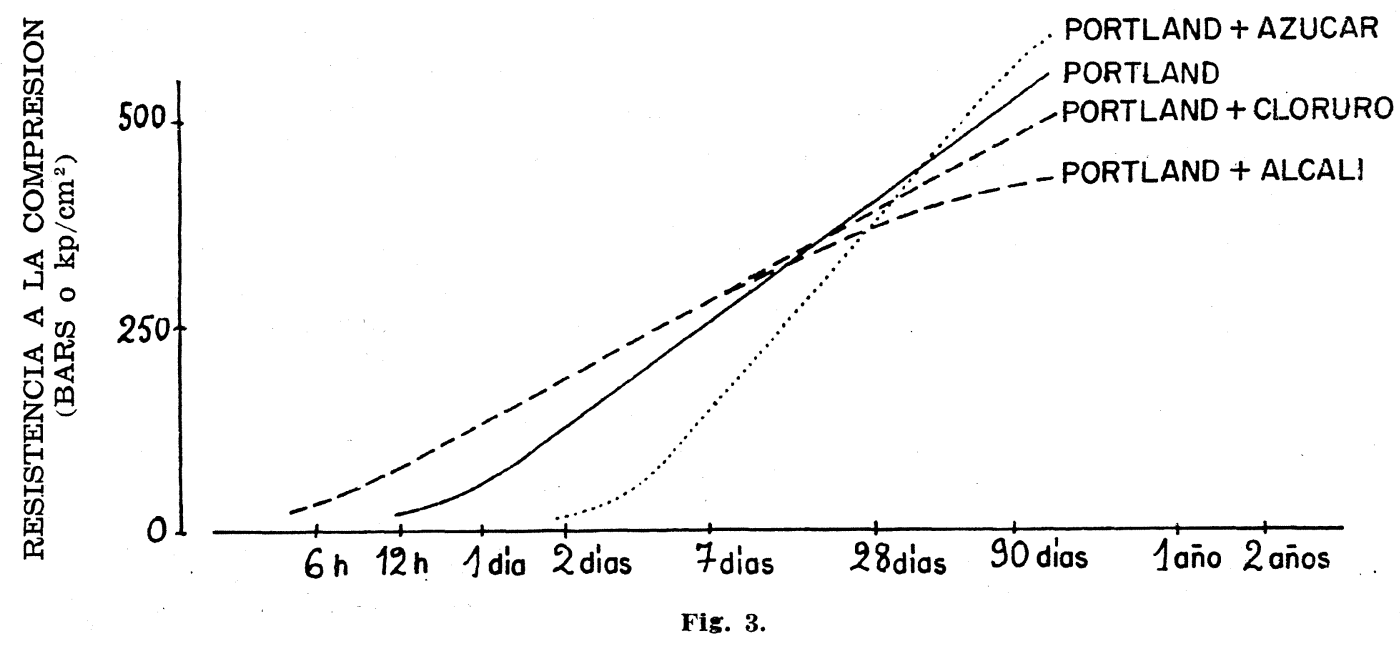

De este modo, el mejor acelerador de los cementos portland es el cloruro cálcico; pero el ion cloruro es peligroso para las armaduras.

A veces, es preciso considerar la actividad de los dos iones del aditivo; por ejemplo, si se añade cloruro cálcico a un cemento sobresulfatado, el ion $\mathrm{Ca}^{++}$no tiene ninguna acción puesto que la solución está saturada en sulfato cálcico y el ion $\mathrm{Cl}^{-}$no puede hacer otra cosa que retardar la disolución de la escoria: este cloruro es, por consiguiente, retardador.

El cemento aluminoso se acelera por los disolventes de la alúmina, constituyente esencial para la hidratación; por lo tanto, por los álcalis, la cal y el clínker de cemento portland; aluminoso y portland no son pues "compatibles". Pero los aluminatos hidratados pueden definirse estequiométricamente, al contrario que los silicatos; estos disolventes favorecen, por tanto, las recristalizaciones y pueden resultar caídas de resistencia importantes. Es por lo que es preciso evitar la mayor parte de los aditivos para el cemento aluminoso.

Los retardadores son poco importantes en prefabricación. Actúan:

- bien como reductcres de solubilidad de los constituyentes del cemento (por ejemplo, la cal grasa retarda al portland);

- bien como colmatadores, formando con la cal silicatos y aluminatos cálcicos, en la superficie de los granos de cemento, compuestos insolubles y anhidros. Por ejemplo, los tetraboratos, fluoruros, fosfatos alcalinos, la mayor parte de los carboxilatos alcalinos (gluconatos en particular) y los azúcares son retardadores.

El sulfato cálcico es un constituyente de la mayor parte de los cementos, pero actúa como un aditivo. $\mathrm{El}$ ion sulfato $\mathrm{SO}_{4}{ }^{=}$es intermedio entre: 
- de una parte, los aniones de ácidos más débiles como la sílice y la alúmina,

- de otra parte, los aniones de ácidos más fuertes como el clorhídrico de los cloruros.

Los principios expuestos explican su comportamiento en los cementos:

A) Para los silicatos cálcicos del cemento, el sulfato es acelerador.

B) Para el aluminato tricálcico de los portland, es retardador y su presencia puede ser indispensable bajo pena de tener un fraguado muy rápido.

En resumen, el yeso es un regulador de fraguado para los cementos portland.

C) Para los aluminatos cálcicos de cementos pobres en cal (aluminoso, escoria, puzolana), el sulfato es acelerador.

Pero para el cemento sobresulfatado constituido principalmente $(85 \%)$ de escoria y de sulfato $(15 \%)$, no es preciso que este sulfato entre muy rápidamente en solución so pena de quedar completamente "congelado" por los primeros aluminatos hidratados que pasen a la solución y no poder intervenir más en la marcha de la hidratación. Por este motivo se emplea una anhidrita cocida en su punto. Sin embargo, si se trata en estufa un hormigón de cemento sobresulfatado, previsto para dar buenas resistencias a la temperatura ordinaria, el sulfato entra muy rápidamente en solución y las resistencias finales son mediocres, como en el caso en que se ha utilizado yeso en lugar de anhidrita en frío.

3) Los aditivos tensoactivos no son ni completamente solubles ni completamente insolubles en el agua de amasado. Sus moléculas orgánicas o siliconadas tienen:

- una extremidad hidrófila conteniendo grupos oxidrilos - $\mathrm{OH}$ o metales alcalinos o calcio;

- una extremidad hidrófoba, por ejemplo un alkilo $-\mathrm{CH}_{3}$ o un núcleo bencénico.

La eficacia de estos aditivos se debe a las burbujas de aire ocluidas gracias a su tensoactividad. Estas burbujas actúan como granos:

- esféricos, por tanto de forma óptima;

- ligeros, pues se oponen a la sedimentación de los granos más pesados que el agua;

- sin frotamiento y, por tanto, fluidificantes;

- numerosos y de un volumen importante (unos 40 litros por $\mathrm{m}^{3}$ de hormigón, para unos 100 litros de cemento en volumen absoluto)'y, por tanto, plastificantes y antihielo;

- pero sin trabazón, por lo que peligran debilitarse las resistencias.

\section{FINURA}

Gracias a su finura, el cemento es un plastificante para el hormigón, y su hidratación se facilita por su gran superficie específica.

Esta finura oscila de un cemento a otro de sencillo a doble: 2.500 a $5.000 \mathrm{~cm}^{2} / \mathrm{g}$ y más.

Las cales hidráulicas tienen una finura del orden de $6.000 \mathrm{~cm}^{2} / \mathrm{g}$ Blaine y las cales grasas del orden de 10.000 . 


\section{ESTABILIDAD A LOS PRODUCTOS EXPANSIVOS}

Los clínkeres portland son tanto más reactivos cuanto más ricos son en cal, es decir, referido a silicatos, cuando su relación $\mathrm{SC}_{3} / \mathrm{SC}_{2}$ es más elevada. Pasado cierto límite, contienen una cierta proporción de "cal libre" $\mathrm{CaO}$ : de 1 a $2 \%$ como máximo, en general.

Parte de esta cal libre, que se encuentra cerca de la superficie de los granos, se hidrata con cierta facilidad durante el almacenamiento del cemento, durante el amasado y, en todo caso, antes del principio del fraguado; por lo tanto, no es peligrosa. Pero si subsiste mucha cal libre en el interior de los granos de clínker, da lugar más tarde a una expansión (como ocurre en la expansión de la cal viva) que puede ser nefasta.

Se concibe que el aumento de la finura sea favorable a la estabilidad frente a los productos expansivos.

La magnesia de los clínkeres proviene de las calizas dolomíticas de ciertas canteras de fábricas de cemento. Una pequeña proporción, algún tanto por ciento, se encuentra en solución en la fase líquida del clínker durante su cocción a $1.450^{\circ} \mathrm{C}$ y permanece en solución sólida en esta "celita" durante su enfriamiento; pasada una cierta proporción cristaliza en parte bajo forma de periclasa. Esta "magnesia libre" juega un papel análogo al de la cal libre, pero la temida expansión es más tardía.

El análisis químico es poco representativo del peligro de expansión de la cal e, incluso, de la magnesia libres. Es por lo que se ideó el ensayo de Le Chatelier. Empleado en caliente acelera la hidratación. Es particularmente indicado para los cementos destinados a los hormigones obtenidos por curado térmico. Para los cementos ricos en magnesia, que se acercan al límite permitido por las normas (5\% en general), el ensayo de autoclave a $216^{\circ} \mathrm{C}$ puede ser necesario.

Las escorias de alto horno no están saturadas en cal. La magnesia aquí se encuentra en estado vítreo bajo forma potencial de silicoaluminato cálcico-magnésico y nunca bajo forma de periclasa, incluso cuando alcanza valores del $18 \%$ para ciertas escorias. Por tanto no es expansiva.

Los constituyentes secundarios (escoria o puzolana) se combinan fácilmente con la cal libre y su presencia aumenta la estabilidad a los componentes expansivos de los cementos portland.

El yeso se combina con los aluminatos hidratados bajo forma de sulfoaluminatos; pero si la proporción de sulfatos es exagerada, el sulfato en exceso reacciona con el aluminato, que se ha hidratado sin saturarse en yeso, provocando una expansión. Por esta razón los cementos que contienen clínker de portland tienen un contenido limitado en sulfatos (este no es el caso en el cemento sobresulfatado). La expansión se comprueba en frío con las agujas de Le Chatelier.

En caliente, la expansión debida a un exceso de yeso es mucho menor que en frío; es necesario suponer que el aluminato se hidrata más deprisa que en frío, con una mayor cantidad de sulfato. Esta es la razón de que los hormigones tratados térmicamente sufran apenas el riesgo de expansión debido a los sulfatos. 


\section{TRABAJABILIDAD}

La trabajabilidad es una cualidad esencial para la prefabricación, sobre la cual tiene una gran influencia el conglomerante (comprendiendo como "conglomerante" el conjunto del cemento, las partículas de granulometría similar y los eventuales aditivos). Conviene definir sin ambigüedades esta trabajabilidad.

La trabajabilidad procede de dos características principales:

- la fluidez, o deformabilidad: Se puede apreciar por la deformación en condiciones determinadas o la velocidad de deformación; el método de medida más simple es el asentamiento en el cono (slump test).

- la insegregabilidad o aptitud a mantenerse homogénea la masa o estabilidad reológica: Se afecta particularmente por la separación, empezando la percolación del constituyente más móvil, es decir, el agua; se puede apreciar por la permeabilidad al agua del hormigón fresco, que puede dar lugar en particular a la exudación. Se da a veces a esta segunda característica el nombre de plasticidad, aunque etimológicamente plasticidad y deformabilidad sean dos términos próximos.

No deben confundirse la fluidez y la insegregabilidad: por ejemplo, el agua puede aumentar la fluidez y, por el contrario, disminuir la insegregabilidad; el aumento de la dosificación de cemento en un hormigón magro y fluido disminuye su fluidez (si se mantiene constante la dosificación de agua) y, por tanto, aumenta la insegregabilidad; el cloruro cálcico es fluidificante, porque aumenta la proporción del líquido de amasado, pero no es plastificante. Sin embargo existen casos en que las dos características van a la par: un oclusor de aire es "fluidificante" y "plastificante" para el hormigón. Como la mayor parte de los fluidificantes son tensoactivos y, por tanto, oclusores de aire, hay a menudo una confusión entre los términos "fluidificante" y "plastificante".

La trabajabilidad de un hormigón puede caracterizarse por medidas llevadas sobre un gráfico (fig. 4).

Mis. 4.-Wh ordienades: In fluidez, por elemplo el asentamilento on el como.

bn alsclkas: la segregabilidad, por ejemplo la exuctacion o verdia die agua en las condiclones thladas.

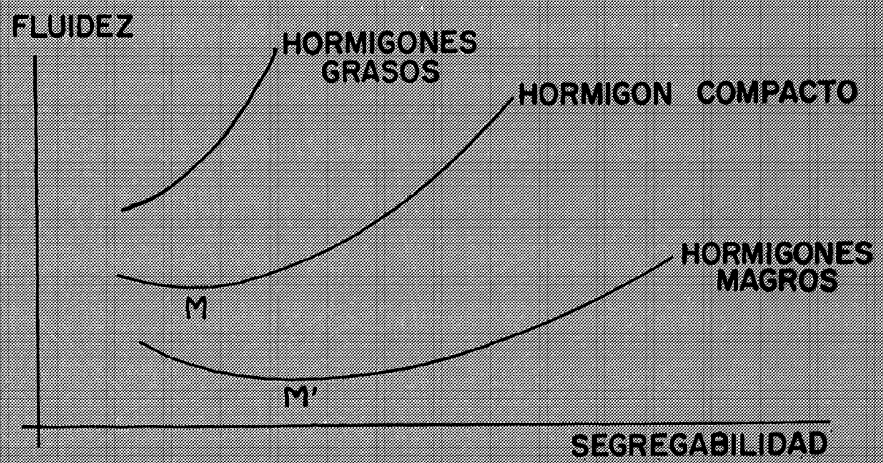

Para un hormigón de granulometría óptima al máximo de compacidad (máximo del volumen absoluto del conjunto árido + cemento), se obtiene una curva tal como la que se indica como "hormigón compacto" sobre la figura 4, al hacer variar la proporción de agua de amasado. Los hormigones "grasos" tienen curvas más altas; los hormigones " $m a-$ gros", curvas más bajas. 
El cemento afecta a la trabajabilidad, no sólo por su dosificación. Influye por su finura, por su composición, y su papel está unido naturalmente al de los aditivos.

Un aumento en la finura del cemento eleva la curva del hormigón sobre el gráfico de la figura 4. Ocurre lo mismo con la adición de "plastificantes" sólidos (kieselgur, arcillas), líquidos (emulsiones de materias "plásticas") o gaseosos (burbujas de aire debidas a productos tensoactivos).

Este aumento de la finura del conglomerante no es, pues, favorable en el caso en que se quiera extraer por presión una parte del agua excedente del hormigón: amiantocemento, hormigonado con vacío.

A igualdad de finura (incluso de superficie específica Blaine), los cementos cuyos granos tienen superficies lisas dan hormigones menos grasos que los portlands. Es el caso en particular de las escorias y de los cementos aluminosos. En cuanto a las puzolanas, se muelen generalmente más finas que los clínkeres; además su volumen absoluto es relativamente grande puesto que su masa volúmica es del orden de 2,6, en tanto que la de los clínkeres es de 3,1; dan, por consiguiente, hormigones relativamente grasos.

La trabajabilidad y el carácter graso o magro se relacionan naturalmente con la capacidad de compactación que se emplea efectivamente en prefabricación.

Si la prefabricación exige paredes lisas, que pueden quedar vistas después del desencofrado, conviene emplear hormigones más bien grasos.

Si exige un desmoldado inmediato, debe reducirse la fluidez y, por tanto, los hormigones deben ser relativamente magros, con una dosificación de agua correspondiente más o menos a los puntos $\mathrm{M}$ o $\mathrm{MI}^{\prime}$ de la figura 4. La rugosidad del hormigón magro es favorable a la buena adherencia de los morteros para juntas o enlucidos. El amasado debe hacerse en una amasadora provista de palas móviles con relación a la cuba y no en una hormigonera.

El aumento de fluidez conferida por una cierta proporción de granos muy finos (cal grasa, kieselgur, oclusor de aire) completada eventualmente con una proporción de agua adecuada, no lleva consigo automáticamente un aumento de las resistencias. Conviene evitar que no enmascare una insuficiente dosificación de cemento.

Las proporciones de los granos iienen tanto mayor importancia, desde el punto de vista reológico, cuanto más finos sean:

- $1 \mathrm{~kg}$ de arcilla tiene más importancia que $1 \mathrm{~kg}$ de cemento;

- $10 \mathrm{~kg}$ de cemento tienen más importancia que $10 \mathrm{~kg}$ de arena;

- $100 \mathrm{~kg}$ de arena tienen más importancia que $100 \mathrm{~kg}$ de piedras gordas.

\section{FRAGUADO}

El fraguado se caracteriza por las primeras modificaciones reológicas debidas a la hidratación del cemento. Es más o menos rápido por las razones que ya se han indicado. Sólo se dirán algunas palabras para distinguir el fraguado del falso fraguado. 
El fraguado del cemento, lo mismo que su endurecimiento, se debe a la hidratación de los granos de este cemento, de los que algunos componentes pasan del estado anhidro a la solución acuosa de los intersticios y precipitan después en estos intersticios asegurando la trabazón entre los granos.

El falso fraguado se debe a una precipitación de cuerpos que se encuentran en solución en el curso del amasado, es decir, aditivos o materias que puedan considerarse como aditivos. En particular, como el agua de amasado está prácticamente saturada en cal (salida del cemento), ésta puede considerarse como un aditivo.

Este falso fraguado, congelación de los intersticios acuosos, da una rigidez análoga a la del fraguado; pero encontrándose los elementos precipitados en pequeña proporción (de 1 a $3 \%$ ), las resistencias son mínimas y el calor de hidratación correspondiente es igualmente reducido.

El falso fraguado ordinario se debe al yeso cocido, que puede proceder del yeso deshidratado parcialmente por elevación de temperatura debida a la molienda del cemento (en ocasiones más de $100^{\circ} \mathrm{C}$ ).

A veces se debe a aditivos especiales, que pueden ser incluso retardadores para el fraguado del cemento cuando se emplean en muy débil dosificación; por ejemplo, los fluoruros alcalinos son poderosos retardadores del portland cuando se emplean en la proporción del $1 \%$, gracias a su precipitación sobre los granos bajo la forma de fluoruro cálcico; pero crean falso fraguado cuando se emplean a razón de algunas unidades por ciento, pues el exceso de fluoruro precipita en los intersticios acuosos en presencia de hidróxido cálcico. El sulfato de hierro provoca, para una proporción análoga, un falso fraguado, aunque sea retardador en pequeñas proporciones, pues da en medio básico un precipitado de hidróxido férrico, etc. Estos productos empleados como aceleradores de fraguado ( $y$ que provocan en realidad un falso fraguado) son, pues, aceleradores de endurecimiento.

La aireación de un portland rico en álcalis puede incluso llevar consigo un falso fraguado, pues provoca la carbonatación de estos álcalis, los cuales entran rápidamente en solución y precipitan en presencia de $\mathrm{Ca}(\mathrm{OH})_{2}$ bajo forma de carbonato cálcico.

El falso fraguado puede favorecer el desmoldado rápido de las piezas prefabricadas, pero las resistencias mecánicas no aumentan de la misma forma.

\section{RESISTENCIAS}

Las resistencias de ios conglomerantes hidráulicos se obtienen:

- en las primeras horas, o incluso en los primeros minutos, por los aluminatos muy cálcicos (caso del cemento rápido);

- a corto plazo (algunas horas), por los aluminatos poco cálcicos (cemento aluminoso), o por los aluminatos muy cálcicos retardados por el yeso (portland rico en $\left.\mathrm{AC}_{3}\right)$;

- a plazo medio (algunos días), por los silicatos muy cálcicos (cemento portland);

- a plazos avanzados (algunos meses), por los silicatos y silicoaluminatos poco cál- 
cicos (cemento de escoria, cemento puzolánico, cemento portland relativamente pobre en cal).

La obtención de estas resistencias puede acelerarse o retardarse, como ya se ha visto (finura, aditivos). La resistencia de un cemento en todas las primeras edades es más o menos proporcional a la finura Blaine (figura 5).

En la prefabricación, la influencia de la temperatura es a veces de capital importancia. La figura 6 indica esquemáticamente el orden de magnitud de las resistencias a la compresión obtenidas para morteros normales ISO (agua/cemento $=0,50$ ) y, en consecuencia, para buenos hormigones corrientes (pilotes de hormigón, por ejemplo), a diversas temperaturas:

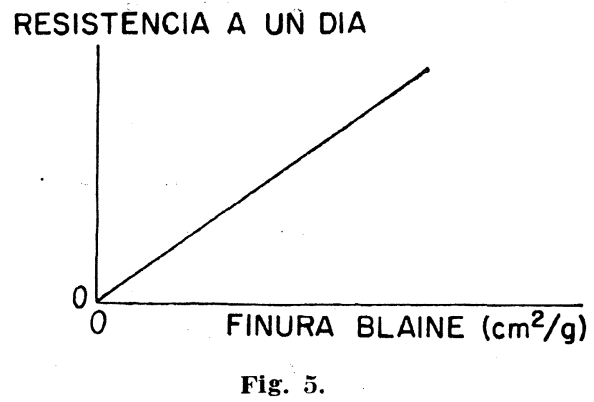

$-\mathrm{P}_{0} \mathrm{P}_{20} \mathrm{P}_{60} \mathrm{P}_{100}:$ hormigones de portland conservados a $0,20,60$ y $100^{\circ} \mathrm{C}$;

$-\mathrm{LP}_{0} \mathrm{LP}_{20} \mathrm{LP}_{60} \mathrm{LP}_{100}$ : hormigones de cemento rico en escoria y, eventualmente, en puzolana;

$-A_{0} A_{20} A_{40}$ : hormigones de cemento aluminoso.

Se puede ver que el empleo de temperaturas elevadas permite lograr con los cementos corrientes, y en unas horas, resistencias análogas a las que se obtienen después de varios días a la temperatura ordinaria; es preciso evitar que una calefacción muy corta a temperatura relativamente alta vaya seguida de cierta desecación durante el enfriamiento.

El tratamiento en estufa no es favorable a los aluminatos y, por tanto, a los cementos aluminosos y a los cementos ricos en aluminato tricálcico (más de 12 a $15 \%$ de $\mathrm{AC}_{3}$ ).

Las resistencias iniciales de los cementos clasificados en la misma categoría normalizada pueden variar considerablemente, a veces de sencillo a triple. En prefabricación es a veces la resistencia del cemento a 24 horas la que es preciso conocer.

Los medios para obtener altas resistencias, y en particular altas resistencias finales, son:

- fuerte dosificación en cemento;

- vibración;

- presión.

La resistencia a la compresión a 28 días (en bars o $\mathrm{kp} / \mathrm{cm}^{2}$ ) de un hormigón corriente medianamente compactado es del orden de la dosificación de cemento (en $\mathrm{kg}$ por metro cúbico) (figura 7).

La resistencia máxima obtenida para un conglomerante hidráulico es 3.500 bars (pasta pura de relación agua/cemento $=0,08$ )

La figura 6 se refiere a una conservación en húmedo; agua o aire saturado. Cuan- 


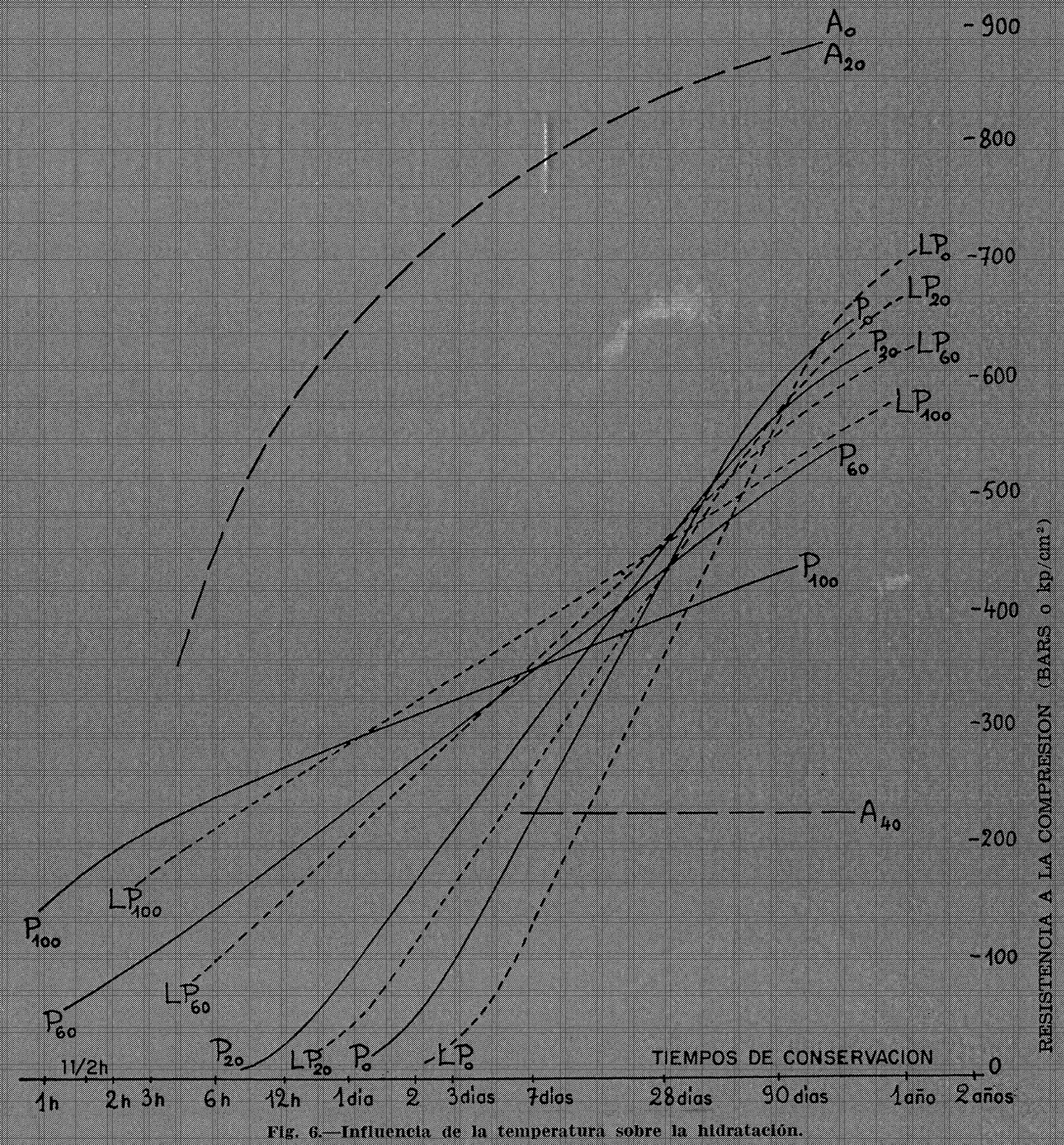

do la atmósfera de conservación no está saturada, se desfavorecen los cementos de hidratación lenta; es el caso particularmente de las escorias y de las puzolanas, las resistencias de las piezas delgadas prefabricadas corren el riesgo de alcanzar el techo relativamente deprisa.

Para ciertas piezas, la resistencia a la tracción es más importante que la resistencia a la compresión.

Las medidas de resistencia (como por otra parte, todas las medidas concernientes 
al hormigón) se encuentran notoriamente dispersas; el coeficiente de variación de las medias de tres probetas es del orden del $10 \%$; es decir, que si la resistencia media es 400 , la resistencia medida (media de 3 probetas) tiene:

2 probabilidades sobre 100 de encontrarse entre 280 y 320 ;

14 probabilidades sobre 100 de encontrarse entre 320 y 360 ;

68 probabilidades sobre 100 de encontrarse entre 360 y 440 ;

14 probabilidades sobre 100 de encontrarse entre 440 y 480 ;

2 probabilidades sobre 100 de encontrarse entre 480 y 520 .

La interpretación de las medidas es, pues, delicada si los ensayos no son bastante numerosos.

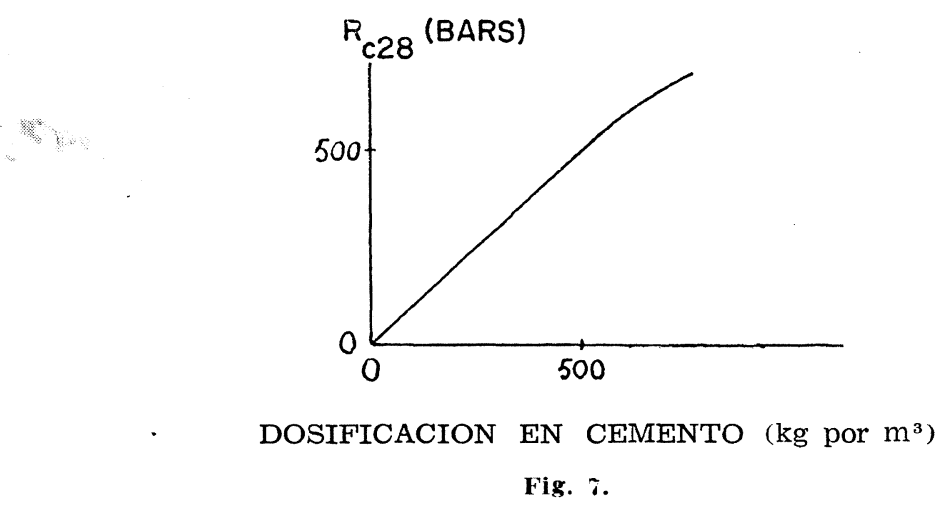

\section{CALOR DE HIDRATACION}

Toda modificación del cemento que lleva consigo una modificación de la resistencia arrastra consigo automáticamente una modificación del calor de hidratación a la misma edad en el mismo sentido. Existe muchas veces proporcionalidad entre lo uno y lo otro.

En prefabricación raramente es de temer una temperatura excesiva del hormigón, y para ciertas piezas se puede incluso utilizar el calor de hidratación para provocar el tratamiento en estufa o al menos contribuir en él. Este es el caso particular del amianto-cemento, que contiene del orden de $85 \%$ de cemento y $15 \%$ do amianto.

La aireación o meteorización del cemento en una atmósfera relativamente húmeda provoca la hidratación preferencial de las partes más hidratables, en particular de los granos más activos y más finos. Son, por tanto, las resistencias iniciales las que más se afectan, así como el calor de hidratación correspondiente.

La meteorización es tanto más de temer cuando el cemento es más fino, en particular para el cemento conservado en sacos de papel. Es menos grave para el cemento exp?dido a granel en recipientes de chapa, como es el caso general en prefabricacion. 
Un cemento todavía "caliente" resulta de una molienda reciente. Es una garantía de calidad, a menos que para ciertos usos se teman las fuertes resistencias y, sobre todo, las fuertes resistencias iniciales; este no es el caso en la prefabricación.

Ciertos cementos recientes pueden, sin embargo, presentar un falso fraguado debido al yeso deshidratado, si están molidos por encima de $100^{\circ} \mathrm{C}$; ya se ha dicho que la aireación de este cemento rehidrata el yeso y suprime el falso fraguado; se puede "romper" este falso fraguado por un amasado suficientemente prolongado (aproximadamente 5 minutos).

Un cemento muy meteorizado puede estar aterronado, sobre todo si es fácilmente hidratable, es decir, si es rico en aluminatos cálcicos y álcalis. Pierde entonces parte de su resistencia, en particular de su resistencia inicial.

\section{RETRACCION}

Un hormigón puesto al aire después de su final de fraguado se retrae, principalmente debido a la tensión superficial del agua que permanece en los intersticios. Esta tensión (o energía) superficial depende de los productos en solución. Se aumenta con las bases y las sales. La "retracción hidráulica" se aumenta, pues, por los álcalis y por los cloruros.

La naturaleza mineralógica de los componentes hidráulicos del cemento no tiene apenas influencia sobre la retracción hidráulica, pero la finura es capital: la retracción hidráulica crece más o menos proporcionalmente con la finura del cemento.

El cemento aluminoso tiene una retracción hidráulica particular: se concibe, según los principios de su hidratación y según su rapidez de endurecimiento y fuerte calor de hidratación, que su retracción hidráulica inicial sea rápida.

Las piezas tratadas en estufa poseen una retracción hidráulica notablemente disminuida; la principal razón es que la hidratación se acelera, en una atmósfera que no está por otra parte siempre saturada; lleva consigo cierta desecación del hormigón y una retracción en el tratamiento en estufa. Más tarde no queda más que tomar una parte de la retracción total.

Si el agua del hormigón puede evaporarse antes del final del fraguado, en particular por viento seco y frío, este hormigón se retrae en cierta manera por presión. La retracción de evaporación antes del final de fraguado es esencialmente distinta de la retracción hidráulica:

- es irreversible, mientras que la retracción hidráulica es en gran parte reversible por rehumidificación;

- es 10 veces mayor que la retracción hidráulica y puede alcanzar varios mm por metro;

- penetra en el hormigón mucho más rápidamente que la retracción hidráulica: la profundidad alcanzada es del orden de:

$$
\mathrm{x}(\mathrm{cm}) \simeq 3 \sqrt{\mathrm{t}} \text { (horas) }
$$


para la retracción antes del fraguado,

$$
\mathrm{x}(\mathrm{cm}) \simeq 0,03 \sqrt{\mathrm{t}} \text { (horas) }
$$

para la retracción hidráulica.

Las cualidades exigidas al cemento no son las mismas para los dos tipos de retracción; son incluso opuestas.

La retracción hidráulica se aumenta con:

- la dosificación de cemento (relativamente poco);

- la dosificación de agua;

- la finura del cemento.

Por el contrario, la retracción de evaporación antes del final del fraguado se aumenta cuando:

- la dosificación de cemento,

- la dosificación de agua,

- la finura del cemento,

disminuyen.

Cualquiera que sea la duración de la conservación húmeda inicial, la retracción hidráulica ulterior de un hormigón es más o menos la misma. Solamente es más lenta para el hormigón viejo que para el hormigón joven, pues la textura de la pasta hidratada es cada vez más cerrada en el curso del endurecimiento. Esta evolución de la velocidad de retracción depende de la naturaleza del cemento; es más importante para un portland que para un aluminoso, y más importante para un cemento de escoria que para un portland.

La retracción térmica debida a las variaciones de temperatura del hormigón es mucho más importante que la retracción hidráulica por su valor, su rapidez y sus alternancias; pero como el hormigón contiene al menos 5 veces más de árido que de cemento, es el coeficiente de dilatación térmica del árido el que tiene una influencia preponderante. En el momento de un enfriamiento, la profundidad alcanzada por la retracción térmica es del orden de:

$$
\mathrm{x}(\mathrm{cm}) \simeq 4 \sqrt{\mathrm{t}} \text { (horas) }
$$

Las piezas de hormigón prefabricado tienen un coeficiente de dilatación térmica del orden de $10^{-5}$ como el acero. Esto hay que tenerlo en cuenta a la hora de realizar una obra, so pena de verla fisurarse, pues el hormigón (sin armar) no tiene más que una resistencia a la tracción de $\approx 100$ veces más pequeña que la del acero.

A menudo se atribuyen fisuras a la "retracción" (se sobreentiende: retracción hidráulica) cuando en realidad se debe a otras causas.

En particular, la existencia de un coeficiente de dilatación térmica del hormigón im- 
pone una velocidad de calefacción y de enfriamiento razonable (inferior a 20 ó $30^{\circ} \mathrm{C} /$ hora para un hormigón que haya hecho su fraguado).

\section{IMPERMEABILIDAD}

La impermeabilidad es primordial para un gran número de piezas prefabricadas: tuberías, tejas, conductos de chimenea, bloques prefabricados, etc. Es también primordial para la perennidad del hormigón (resistencia a los agentes agresivos, al hielo, protección de las armaduras). No puede lograrse para el hormigón endurecido más que si se ha obtenido para el hormigón fresco, es decir, para hormigones "compactos" o "grasos" (figura 4), es una condición sine qua non. Esto impone para el cemento:

- una dosificación suficiente,

- una finura suficiente.

La impermeabilidad puede mejorarse por aditivos hidrófugos que son esencialmente mezclas:

- de granos muy finos sólidos o a veces líquidos, para completar eventualmente la granulometría del cemento;

- fluidificantes para disminuir la proporción de agua de amasado;

- materias precipitables en los intersticios acuosos iniciales, en presencia de la cal en solución: silicatos, fluosilicatos, sulfatos, jabones, etc..

La impermeabilidad exige que los intersticios acuosos se transformen en geles lo más concentrados posible y, en consecuencia, que la hidratación sea lo más completa posible. Es, pues, necesaria una conservación en húmedo, tanto más prolongada cuanto el cemento sea menos hidratable (cementos de escoria, cementos puzolánicos).

De una manera general, la permeabilidad y la capilaridad van a la par, pero hay excepciones: un hormigón cavernoso puede ser muy permeable y muy poco absorbente.

\section{RESISTENCIA A LAS AGUAS Y A LOS VAPORES AGRESIVOS}

La primera cualidad de un hormigón para resistir a los agentes agresivos y la más importante es la impermeabilidad. Así se explica que el aumento de la dosificación de cemento sea siempre favorable, aunque sea el cemento el componente atacable.

En cuanto a la naturaleza del cemento, aunque sea secundaria, debe tenerse en cuenta para tener el máximo de seguridad que:

- para resistir a las aguas puras o ácidas que disuelven la cal, es mejor emplear cementos poco cálcicos: cementos de escoria, cementos puzolánicos, portlands poco cálcicos ;

- para resistir a los sulfatos, que dan con los aluminatos y sulfoaluminatos hidratados un sulfoaluminato muy sulfatado y expansivo, y que movilizan la cal, es mejor emplear cementos que no contengan más que una pequeña proporción de 
$\mathrm{AC}_{3}$ y relativamente pobres en cal: cementos de escoria, cementos puzolánicos, portlands pobres en $\mathrm{AC}_{3}$ y relativamente poco cálcicos.

\section{RESISTENCIA AL HIELO}

Los elementos prefabricados emplazados donde corran el riesgo de estar embebidos de agua y sometidos al hielo, deben ante todo ser impermeables. Esto supone para el cemento, como para la resistencia a los agentes agresivos:

- una dosificación suficiente;

- una finura suficiente.

El cemento debe hidratarse rápidamente en el curso del fraguado para evitar el rezumado interno del agua, que constituye bajo los granos del hormigón meniscos que corren el riesgo de estar saturados de agua y de hinchar bajo el efecto de la helada. Por eso no son recomendables las fuertes proporciones de puzolana y mucho menos las de harinas pétreas.

Si se emplean áridos reactivos, que corren el riesgo de provocar expansiones por combinación de su sílice vítrea con los álcalis del clínker portland, es preciso emplear un cemento puzolánico, con un $20 \%$ de puzolana aproximadamente, ya que esta puzolana forma con los álcalis liberados por hidratación del clínker compuestos hidratados estables. Los álcalis de la puzolana, que pueden encontrarse en notables proporciones, no son peligrosos. También se puede emplear un portland de débil proporción de álcalis (menos de $0,5 \%$ de $\mathrm{Na}_{2} \mathrm{O}+\mathrm{K}_{2} \mathrm{O}$ ), pero la fabricación moderna del clínker por vía seca tiende a dar un producto que contiene una proporción relativamente elevada de álcalis. La eliminación de estos álcalis impone una adición de cloruro cálcico al crudo, lo que complica la fabricación y provoca corrosiones en las instalaciones.

El cemento debe ser perfectamente estable a los expansivos, con objeto de que las expansiones de la cal y la magnesia libres no se añadan a las del hielo.

La resistencia a la helada puede mejorarse por aditivos tensoactivos, que incorporan al hormigón gran cantidad de finas burbujas de aire distantes entre sí alrededor de $0,1 \mathrm{~mm}$ y que sirven de vasos de expansión para el hielo que tienda a formarse.

\section{PROTECCION DE LAS ARMADURAS}

La oxidación de las armaduras del hormigón armado y del hormigón pretensado es, esencialmente, electroquímica: toda heterogeneidad del metal, de su naturaleza, de su tensión, o de su medio electrolítico constituido por el hormigón, da lugar a la formación de pilas; las partes anódicas abandonan electrones en la masa del metal y pueden así ionizarse bajo forma de sales en presencia de aniones $\mathrm{Cl}^{-}, \mathrm{CO}_{3}{ }^{=}, \mathrm{OH}^{-}$, etc. La oxidación (es decir, la separación de electrones del metal) no puede tener lugar, como en las pilas corrientes, más que si los cátodos están despolarizados por oxidantes, en particular por protones $\mathrm{H}^{+}$. El papel del hidrógeno es primordial aunque sea menos electropositivo que el hierro, pues es un metal gaseoso y sus aniones muy pequeños y particularmente móviles, incluso en el acero. El cemento, hecho básico por la hidratación, aumenta la concentración de iones $\mathrm{OH}^{-}$en el agua (gracias a la fuerte electropositividad del calcio) y, automática- 
mente, disminuye la concentración de $\mathrm{H}^{+}$. Es por lo que pasiva el acero permitiendo la polarización de los cátodos a un pH elevado.

La composición de los cementos más favorable para la protección de las armaduras es pues la más cálcica.

Pero la naturaleza es rica en ácidos; en particular, el ácido carbónico de la atmósfera carbonata la cal, y rebaja el $\mathrm{pH}$ por debajo de 9, poniendo fin a la pasivación. La oxidación se acelera entonces por los electrólitos, sobre todo por los electrólitos fuertes, por ejemplo los cloruros y los nitratos, que son muy solubles y además higroscópicos.

Así, la protección de las armaduras exige:

- un espesor de hormigón suficiente;

- una buena impermeabilidad al ácido carbónico.

La cal hidráulica y todavía más la cal grasa son menos favorables que el portland, pues ambas dan hormigones relativamente permeables.

El yeso no es favorable para la protección de las armaduras, ya que es poroso, y el sulfato es una sal de ácido fuerte.

Los cementos ricos en sulfato no son precisamente favorables; solamente una proporción moderada de sulfato se puede fijar por los aluminatos hidratados. El cemento sobresulfatado no es indicado para piezas armadas, donde es de temer la oxidación.

Los clínkeres cocidos en atmósfera reductora, al menos localmente en ciertos hornos, pueden contener una pequeña proporción de sulfuros (hasta $1 \%$ de $\mathrm{S}^{=}$). Ocurre lo mismo en la mayor parte de las escorias de alto horno. En presencia de agua, estos sulfuros dan ácido sulfídrico $\mathrm{SH}_{2}$, detectable por el olor y ligeramente ácido. Sería contrario a los principios de la química que los sulfuros fueran globalmente más oxidantes que los sulfatos correspondientes; pero su repartición en los granos de cemento es a veces heterogénea y sobre todo los caminos preferenciales seguidos por el $\mathrm{SH}_{2}$ pueden favorecer la oxidación local si la carbonatación ha puesto fin a la pasivación. Esto puede explicar ciertos accidentes observados en hormigones pretensados cuyo espesor de hormigón sobre las armaduras era insuficiente, en la que la dosificación de cemento era más bien baja y que el cemento no era bastante cálcico.

\section{RESISTENCIA A LAS ALTAS TEMPERATURAS}

Los conglomerantes hidráulicos pierden su agua "libre" o relativamente libre cuando se eleva la temperatura. A partir de $400^{\circ} \mathrm{C}$, el hidróxido cálcico pierde una molécula de agua $\left(\mathrm{Ca}(\mathrm{OH})_{2} \longrightarrow \mathrm{CaO}+\mathrm{H}_{2} \mathrm{O}\right)$; y a partir de $600^{\circ} \mathrm{C}$, el carbonato cálcico pierde una molécula de anhídrido carbónico $\left(\mathrm{CaCO}_{3} \longrightarrow \mathrm{CaO}+\mathrm{Co}_{2}\right)$. Por enfriamiento y mojado posterior, la cal viva formada se hidrata con hinchamiento y pulverización.

Los cementos portland no pueden emplearse por encima de $400^{\circ} \mathrm{C}$.

Los cementos menos cálcicos, en particular los cementos puzolánicos, resisten un poco mejor que los portland; pero si se quieren realizar verdaderos hormigones refractarios, es preciso emplear cementos aluminosos. 
El cemento aluminoso corriente resiste $1.400^{\circ} \mathrm{C}$. Si se quiere que el hormigón resista temperaturas superiores, es preciso emplear cementos aluminosos cuyo contenido en alúmina sea superior.

\section{ASPECTO DE LAS SUPERFICIES}

La uniformidad de las superficies obtenidas al desencofrar o después del pulido, es función de la trabajabilidad original del hormigón.

La uniformidad de color del cemento es función del clínker y de los constituyentes secundarios. Puede obtenerse gracias a una buena regularidad de la fabricación:

- composición del clínker;

- procedencia de los constituyentes secundarios;

- finura.

El color de las superficies desencofradas depende, esencialmente, del de los granos finos. Un color blanco exige un cemento sin óxido de hierro y sin manganeso: cemento portland blanco y ciertas cales hidráulicas.

El color blanco se mejora añadiendo al cemento una harina silícea; si las piezas están tratadas en autoclave, esta sílice se combina con la cal liberada por la hidratación del cemento o con la cal grasa y contribuye así a la obtención de resistencias: es un conglomerante sílico-calcáreo.

Los colores variados se obtienen por adición de óxidos metálicos insolubles en agua.

\section{PRECIO}

El precio del cemento es con frecuencia un elemento importante de la prefabricación. No es nunca el elemento económico principal. A menudo, en las piezas prefabricadas, que son extremadamente variadas, los gastos principales son los del árido, la mano de obra, los gastos generales, e incluso los impuestos.

De todos modos, el cemento es un elemento capital para las diversas calidades de piezas prefabricadas. Esto no se debe despreciar a la hora de su elección o, eventualmente, de su dosificación.

\section{CONCLUSION}

La prefabricación ha tomado desde hace 20 años un impulso importante, a veces prodigioso, que no puede más que acentuarse en el porvenir. El hormigón sigue así la evolución general e irreversible de todos los productos fabricados.

La industria del cemento deberá continuar adaptándose a esta evolución produciendo cementos cada vez más regulares desde el punto de vista de sus diversas características, siempre más rápidos en su endurecimiento y siempre más económicos.

Esto impondrá a las fábricas de cemento aumentar sus producciones con máquinas potentes, tanto para la extracción de materiales en cantera como en la homogeneización, cocción, molienda y expedición. El fưncionamiento de estas máquinas deberá asegurarse con el máximo de regularidad y con un control fisicoquímico riguroso. 